Alignment: Journal of Administration and Educational Management

Volume 1, Nomor 1, Juni 2018

e-ISSN : 2598-5159

p-ISSN : 2598-0742

DOI : https://doi.org/10.31539/alignment.v1i1.276

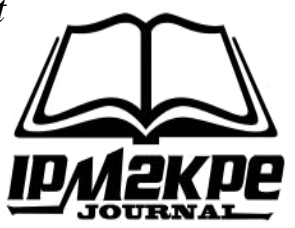

\title{
MANAJEMEN TENAGA PENDIDIK SDIT MUTIARA CENDEKIA LUBUKLINGGAU
}

\author{
M. Rusni Eka Putra ${ }^{1}$, Ahmad Gawdy Prananosa ${ }^{2}$, Marianita ${ }^{3}$ \\ STKIP PGRI Lubuklinggau ${ }^{1,2,3}$ \\ Putra70_eka@ymail.com ${ }^{1}$
}

\begin{abstract}
ABSTRAK
Penelitian ini bertujuan ntuk mengetahui perencanaan, pelaksanaan, control dan evaluasi tenaga pendidik di SD IT Mutiara Cendekia Lubuklinggau. Penelitian ini menggunakan pendekatan kualitatif dengan metode deskiriftif kualitatif. Subyek penelitian terdiri dari kepala sekolah, dewan guru dan staf, wali murid SD IT Mutiara Cendekia Lubuklinggau. Hasil penelitian, perencanaan tenaga pendidik dilakukan dengan baik seperti ratio guru dan siswa (2/22) sangatlah relevan dalam proses belajar dan mengajar. Simpulan dalam penelitian ini, yakni 1), perencanaan tenaga pendidik SD IT Mutiara Cendekia Lubuklinggau berjalan dengan baik yakni merekrut tenaga pendidik dengan menyeleksi administrasi berkas lamaran pekerjaan dan tes kemampuan baca al-Qur'an serta tes micro teaching, 2) pelaksananaan tenaga pendidik melalui pembinaan dari yayasan dua kali sebulan, pelatihan kurikulum 2013 dan seminar pengembangan mutu guru, 3) kepala sekolah mengontrol tenaga pendidik dengan cara berkeliling ke ruang belajar selama proses pembelajaran berlangsung, memeriksa absensi tenaga pendidik melalui finger print, dan jurnal pembelajaran di dalam kelas, 4) kepala sekolah menggunakan angket, kemudian disebarkan kepada siswa sehingga masukkan-masukkan mengenai tenaga pendidik dalam menjalankan tugasnya dapat diketahui dan dilakukan pembinaan oleh kepala sekolah.
\end{abstract}

Kata Kunci: Manajemen, Tenaga Pendidik

\begin{abstract}
This study aims to determine the planning, implementation, control and evaluation of educators at SD IT Mutiara Cendekia Lubuklinggau. This study uses a qualitative approach with qualitative descriptive methods. The research subjects consisted of the principal, the board of teachers and staff, the guardians of elementary students of IT Mutiara Mutiara Scholar Lubuklinggau. The results of the study, the planning of educators is done well as the teacher and student ratio (2/22) is very relevant in the learning and teaching process. Conclusions in this study, namely 1), the planning of Mutiara IT Scholar SD Lubuklinggau elementary school educators went well namely recruiting educators by selecting the administration of job application files and the ability to read al-Qur'an as well as micro teaching tests, 2) the implementation of educators through coaching from the foundation twice a month, 2013 curriculum training and teacher quality development seminars, 3) the principal controls the
\end{abstract}


teaching staff by going around the learning room during the learning process, checking the attendance of educators through finger print, and learning journals in the classroom, 4 ) the school principal uses a questionnaire, and then disseminates it to students so that the information about the teaching staff in carrying out their tasks can be known and provided guidance by the school principal.

\section{Keywords: Management, Educators}

\section{PENDAHULUAN}

Sekolah sebagai sistem memiliki komponen yang saling terkait dan saling mempengaruhi dalam mencapai tujuan organisasi. Input sekolah meliputi: siswa, tenaga pendidik, keuangan, serta instrumental dan environmental input lainnya harus dapat didayagunakan seefektif mungkin dalam proses transformasi, untuk menghasilkan output berupa peserta didik yang memiliki seperangkat nilai, sikap, pengetahuan serta keterampilan baru. Mendayagunakan semua sumber daya tersebut, diperlukan pengelolaan sekolah yang baik.

Penyelenggaraan Sekolah sesuai dengan standar nasional pendidikan yang dirumuskan oleh Pemerintah. Standarisasi yang dimaksud menurut Peraturan Pemerintah Nomor 19 tahun 2005 meliputi standar pendidik tenaga kependidikan, standar proses, standar isi, standar pembiayaan, standar sarana prasarana, standar pengelolaan, standar kompetensi lulusan, dan standar penilaian. Adanya standarisasi, maka dapat meningkatkan kualitas sekolah, sehingga sekolah Islam terpadu mampu bersaing dengan sekolah lainnya. Apalagi dalam proses pengelolaan pendidikan, pemerintah telah mendorong adanya otonomi pendidikan. Dengan demikian Sekolah bisa lebih leluasa dalam melakukan proses manajemen sekolah yang mengarah pada peningkatan mutu Sekolah.

Sekolah disamping menyediakan pendidikan umum, juga menyiapkan pendidikan agama berbasis karakter. Hasil penelitian Muzyanah (2014) menyatakan bahwasanya pendidikan karakter sudah termasuk dalam pengelolaan sekolah. Pengelolaan sekolah sudah terintegrasi dalam menyiapkan peserta didik untuk mendapatkan keilmuan scientific tanpa meninggalkan ilmu agama. Sebenarnya manajemen Sekolah memiliki potensi keunggulan-kenggulan dari lembaga pendidikan umum.

Mewujudkan pendidikan sekolah yang unggul diperlukan komponen pendukung, seperti komponen tenaga pendidik, sarana dan prasarana, kurikulum, kesiswaan, keuangan dan kepemimpinan kepala sekolah. Hasil penelitian Hidayati (2014) menjelaskan sebagai berikut: kepemimpinan pendidikan yang baik sangat mempengaruhi mutu pendidikan. Peran kepemimpinan pendidikan sangat menunjang keberhasilan tenaga pendidik. 
Kepemimpinan memegang peranan penting dalam pengelolaan sekolah, seluruh komponen sekolah digerakkan oleh kepala sekolah dengan skill dan kemampuannya. Kepala sekolah berupaya untuk mempengaruhi seluruh warga sekolah untuk mencapai visi dan misi sekolah, sehingga tujuan sekolah yang telah direncanakan dapat tercapai. Menurut hasil penelitian Suwardi dan Samino (2014) menjelaskan diperlukan tipe kepemimpinan demokratis dan pendekatan akhlaqi dalam mencapai tujuan organisasi .

Peran kepemimpinan dalam mengelola tenaga pendidik sangatlah penting dalam pengelolaan sekolah. Menurut hasil penelitian Manaf (2013) menyatakan latar belakang pendidikan kepala sekolah, latar belakang Tenaga Pendidik serta keterampilan Tenaga Pendidik menguasai metode, bahan dan media pembelajaran menjadi faktor kesuksesan sekolah. Jelas bahwasanya kepala sekolah, kemudian penguasaan tenaga pendidik terhadap metode, bahan dan media pembelajaran sangatlah berpengaruh dalam meningkatkan mutu sekolah.

Kepemimpinan merupakan energi yang dapat menggerakkan, menuntun dan menjaga aktivitas orang sehingga tujuan organisasi dapat tercapai. Sangat besar dampak atau pengaruh pemimpin terhadap bawahan, sehingga bawahan dapat bekerja dengan baik dan sesuai dengan apa yang telah digariskan dalam tujuan organisasi. Dilingkungan sekolah pemimpin yang tertinggi adalah kepala sekolah, dengan kreatifitas dan motivasinya kepala sekolah dapat mengarahkan, membimbing dan memotivasi tenaga pendidik dan karyawan lainnya untuk bekerjasama dalam memajukan sekolah. Kepemimpinan kepala sekolah tidak hanya sebatas kepemimpinan formal, artinya tidak hanya sekedar menjalankan tugas dan tanggungjawab, namun diperlukan inovasi dan kreatifitas kepala sekolah dalam meningkatkan prestasi sekolah baik secara akademik maupun non akademik.

Peningkatan mutu pendidikan ditentukan oleh kesiapan sumber daya manusia yang terlibat dalam proses pendidikan. Tenaga pendidik merupakan salah satu faktor penentu tinggi rendahnya mutu hasil pendidikan mempunyai posisi strategis maka setiap usaha peningkatan mutu pendidikan perlu memberikan perhatian besar kepada peningkatan tenaga pendidik baik dalam segi jumlah maupun mutunya.Tenaga pendidik adalah figur manusia sumber yang menempati posisi dan memegang peran penting dalam pendidikan. Ketika semua orang mempersoalkan masalah dunia pendidikan figur tenaga pendidik mesti terlibat dalam agenda pembicaraan terutama yang menyangkut persoalan pendidikan formal di sekolah.

Tenaga pendidik merupakan tenaga profesional yang bertugas merencanakan dan melaksanakan proses pembelajaran, menilai hasil pembelajaran, melakukan pembimbingan dan pelatihan, serta melakukan penelitian dan pengabdian kepada masyarakat. Hal tersebut tidak dapat disangkal karena lembaga pendidikan formal 
adalah dunia kehidupan tenaga pendidik.Sebagai besar waktu tenaga pendidik ada di sekolah, sisanya ada di rumah dan di masyarakat .

Tenaga pendidik sebagai pekerja harus berkemampuan yang meliputi penguasaan materi pelajaran, penguasaan profesional tenaga pendidik dan pendidikan, penguasaan cara-cara menyesuaikan diri dan berkepribadian untuk melaksanakan tugasnya, disamping itu tenaga pendidik harus merupakan pribadi yang berkembang dan bersifat dinamis. Hal ini sesuai dengan yang tertuang dalam Undang-undang No. 20 tahun 2003 tentang Sistem Pendidikan Nasional bahwa pendidik dan tenaga kependidikan berkewajiban 1) menciptakan suasana pendidikan yang bermakna, menyenangkan, kreatif, dinamis, dan dialogis, 2) mempunyai komitmen secara profesional untuk meningkatkan mutu pendidikan dan 3) memberi teladan dan menjaga nama baik lembaga, profesi, dan kedudukan sesuai dengan kepercayaan yang diberikan kepadanya.

Harapan dalam Undang-Undang tersebut menunjukkan adanya perubahan paradigma pola mengajar tenaga pendidik yang pada mulanya sebagai sumber informasi bagi siswa dan selalu mendominasi kegiatan dalam kelas berubah menuju paradigma yang memposisikan tenaga pendidik sebagai fasilitator dalam proses pembelajaran dan selalu terjadi interaksi antara tenaga pendidik dengan siswa maupun siswa dengan siswa dalam kelas. Kenyataan ini mengharuskan tenaga pendidik untuk selalu meningkatkan kemampuannya terutama memberikan keteladanan, membangun kemauan, dan mengembangkan kreativitas peserta didik dalam proses pembelajaran.

Tenaga pendidik merupakan faktor yang sangat dominan dan paling penting dalam pendidikan formal pada umumnya karena bagi siswa tenaga pendidik sering dijadikan tokoh teladan bahkan menjadi tokoh identifikasi diri. Tenaga pendidik merupakan unsur yang sangat mempengaruhi tercapainya tujuan pendidikan selain unsur murid dan fasilitas lainnya. Keberhasilan penyelenggaraan pendidikan sangat ditentukan kesiapan tenaga pendidik dalam mempersiapkan peserta didiknya melalui kegiatan belajar mengajar. Namun demikian posisi strategis tenaga pendidik untuk meningkatkan mutu hasil pendidikan sangat dipengaruhi oleh kemampuan profesional tenaga pendidik dan mutu kinerjanya. Begitu juga dengan tenaga pendidikan yang segala administrasi sekolah, sehingga arsip-arsip dan database komponen sekolah dapat terkelola dan terpelihara dengan baik. Tenaga pendidik menjadi bagian yang terpenting bagi sekolah dalam mencapai visi dan misi sekolah.

Kepala sekolah bertanggungjawab terhadap sukses atau tidaknya sekolah yang dipimpin, kepala sekolah merupakan faktor kunci, karena kepala sekolah memegang peranan penting dalam pengelolaan sekolah. Pembinaan terhadap tenaga pendidik merupaka salah satu tugas dari kepala sekolah sebagai pemimpin sekolah, namun dalam pembinaan terhadap tenaga pendidik masih sangat memprihatinkan, program 
dan kegiatan pembinaan serta pengembangan kompetensi tenaga pendidik, khususnya komponen-komponen profesional.

Berdasarkan observasi awal peneliti bahwasanya SDIT Mutiara Cendekia dari tahun ke tahun mengalami kemajuan yang signifikan terutama dalam jumlah siswa yang masuk, tingginya minat orang tua, kemudian fasilitas sekolah yang cukup untuk mendukung pelaksananan pembelajaran. Begitu juga hasil wawancara dengan wali murid, bahwasanya biaya sekolah (SPP) terjangkau, kemudian proses pembelajaran menyenangkan, fullday school dan ekstrakurikuler (pramuka, seni baca al-qur`an, pidato, keagamaan, bahasa inggris). Hasil wawancara dengan walimurid yang menyatakan bahwasanya tenaga pendidik sudah sesuai dengan standar pemerintah, yakni satu kelas didampingi oleh 2 orang tenaga pendidik. Sehingga proses belajar dan mengajar di dalam kelas dapat terlaksana dengan kondusif.

Memang tolak ukur kemajuan suatu sekolah tidak hanya dapat diukur dari input siswa yang tinggi, namun faktor kualitas tenaga pendidik yang memberikan pengajaran kepada siswa juga sangat menentukan. Setiap satu kelas didampingi oleh 2 orang tenaga pendidik, sehingga memberikan pelayanan pengajaran dan pendidikan kepada siswa sangat intensif. Pengelolaan tenaga pendidik sangatlah perlu diperhatikan dalam upaya peningkatan mutu sekolah

\section{METODE PENELITIAN}

Penelitian ini menggunakan pendekatan kualitatif dengan metode deskiriftif kualitatif. Subyek penelitian terdiri dari kepala sekolah, dewan guru dan staf, wali murid SDIT Mutiara Cendikian Lubuklinggau. Sumber data dalam penelitian ini dapat dibedakan menjadi dua, yaitu manusia (human) dan bukan manusia.Sumber data manusia berfungsi sebagai subjek atau informan kunci (key informan) dan data yang diperoleh melalui informan berupa soft data (data lunak) seperti hasil wawancara dan observasi dengan kepala sekolah, guru dan wali siswa. Sedangkan sumber data bukan manusia berupa dokumen yang relevan dengan permasalahan penelitian, seperti peristiwa atau aktifitas yang ada kaitannya dengan permasalahan penelitian. Data yang diperoleh melalui dokumen bersifat hard data (data keras) yang berkenanaan dengan data Sekolah.

Pada penelitian ini menggunakan metode pengumpulan data observasi, wawancara dan dokumentasi. Untuk menetapkan keabsahan (trustworthiness) data diperlukan teknik pemeriksaan. Ada empat kreteria yang dapat digunakan untuk menguji keabsahan data, yaitu derajat kepercayaan (credibility), keteralihan (transferability), ketergantungan (dependability) dan kepastian akan data dan hasil penelitian. Disamping itu juga dilakukan triangulasi. Trianggulasi yaitu pemeriksaan silang dari berbagai sumber yang digunakan. Triangulasi yang banyak digunakan adalah triangulasi dengan sumber yaitu membandingkan dan mengecek balik derajat 
kepercayaan suatu informasi yang diperoleh melalui waktu dan alat yang berbeda dalam penelitian.

Lebih jelasnya trianggulasi dilakukan dengan jalan 1).membandingkan data hasil wawancara dengan hasil pengamatan, 2). membandingkan apa yang dikatakan orang di depan umum dengan apa yang dikatakan secara pribadi, 3). membandingkan apa yang dikatakan orang tentang tentang situasi penelitian dengan apa yang dikatakan sepanjang waktu, 4). membandingkan keadaan dan perspektif seseorang dengan berbagai pandangan orang dari berbagai latar belakang, 5). membandingkan hasil wawancara dengan isi dokumen yang berkaitan.Trianggulasi dilakukan bersamaan dengan kegiatan pengamatan dilapangan, sehingga peneliti bisa melakukan pencatatan data secara lengkap. Dengan demikian maka data hasil penelitian ini layak untuk dimanfaatkan.

teknik analisis data penelitian kualitatif dalam pengumpulan datanya menggunakan teknik; editing, kategori, mendisplay data dan penafsiran.

\section{HASIL DAN PEMBAHASAN \\ Perencanaan Tenaga Pendidik}

Berdasarkan hasil wawancara di atas bahwasanya perencanaan tenaga pendidik dilakukan dengan baik seperti ratio guru dan siswa (2/22) sangatlah relevan dalam proses belajar dan mengajar. Disamping itu Kepala Sekolah memetakan kebutuhan guru dan karyawan berdasarkan spesifikasi dan keahlian yang dibutuhkan Sekolah2 (dua) bulan sebelum semester ganjil/genap berakhir dan mengajukan surat permohonan kebutuhan guru/karyawan kepada pengurus yayasan.

Pengurus yayasan mengeluarkan kebijakan perihal penerimaan guru dan karyawan minimal 1 minggu setelah surat permohonan diterima. Kemudian kepala Sekolah mengumumkan tentang adanya lowongan pekerjaan secara luas melaui brosur pengumuman, dan media sosial maupun secara lisan minimal 1 hari setelah yayasan mengeluarkan kebijakan. Lama pendaftaran penerimaan guru/karyawan +3 (tiga) minggu.

Kemampuan dan latar belakang pendidikan guru, sangatlah diperhatikan di SDIT Mutiara Cendekia Lubuklinggau dalam rangka mendukung proses belajar dan mengajar dengan baik, sehingga dapat berdampak pada pencapai prestasi belajar siswa baik secara akademik maupun non akademik. Kemudian dalam perekrutan guru melakukan test kemampuan baca-tulis al-qur`an dan test micro teaching dalam menyampaikan materi pembelajaran. Kedua test tersebut sebagai modal bagi guru dalam menjalankan tugas pokok dan fungsinya sebagai tenaga pengajar dan pendidik 
Kemudian dilakukan rekam jejak kepada calon tenaga pendidik baik melalu wawancara kepada calon tenaga pendidik maupun dengan pencarian informasi dengan teman dekat yang dikenal dan dapat memberikan informasi mengenai kondisi, keadaan dan pengalaman calon tenaga pendidik

\section{Pelaksanaan Tenaga pendidik}

Berdasarkan hasil wawancara di atas, maka pelaksanaan tenaga pendidikSDIT Mutiara Cendekia Lubuklinggauadalah sebagai berikut, pola rekrutmen tenaga pendidik yakni sebagai berikut:

Seleksi administrasi berkas lamaran pekerjaan.

Seleksi awal dilaksanakan setelah pelamar lulus pada seleksi administrasi, seleksi ini meliputi test kemampuan baca al-qur'an dan test micro teaching untuk pelamar guru. Seleksi awal ini dilakasanakan oleh Sekolah.

Seleksi Akhir dilaksanakan setelah pelamar lulus seleksi awal. Seleksi ini dilaksanakan oleh yayasan.

SDIT Mutiara Cendekia Lubuklinggaumemberikan pembinaan kepada guru dengan metode yanbu'a, seperti membaca al-qur'an mengkaji kitab fathul qorib dan matan takrib yang dilaksanakan secara terjadwal, kemudian pembinaan dari yayasan dilaksanakan satu bulan sebanyak 2 kali, rutin pelatihan kurikulum 2013 dan seminar pengembangan mutu guru yang professional.

Kemudian kepala sekolah selama bertugas tidak pernah mengalami tenaga pendidik melakukan pelanggaran, sebab kepala sekolah menggunakan pendekatan persaudaraan sehingga guru dan TU menjalankan tugasnya atas kesadaran, bukan atas keterpaksaan kepala sekolah. Kemudian juga setiap tenaga pendidik membuat pernyataan jika melakukan kesalahan siap menerima sanksi yang setimpal sesuai dengan kesalahan yang telah dilakukan.

SDIT Mutiara Cendekia Lubuklinggau sangat menekan kedisiplinan bagi tenaga pendidik, penerapan kedisiplinan tersebut dengan memanfaatkan teknologi informasi, yakni (finger print), sehingga ketika guru datang melakukan absensi dan begitu juga jikalau pulang melakukan absensi sesuai dengan jam kepulangan. Kemudian memberikan reward atau hadiah kepada tenaga pendidik yang berprestasi dalam bekerja seperti pemberian piagam dan bingkisan. Pemberian reward ini semata-mata untuk meningkatkan prestasi kerja tenaga pendidik dalam menjalankan tugas pokok dan fungsinya masing-masing.

\section{Kontrol Tenaga Pendidik}

Berdasarkan hasil wawancara di atas, maka kontrol tenaga pendidik diSD IT Mutiara Cendekia Lubuklinggau sebagai berikut; tingkah laku tenaga pendidik sangatlah diperhatikan oleh kepala sekolah. Kepala sekolah sering keliling ruangan 
setiap proses pembelajaran berlangsung dan kemudian kepala sekolah memeriksa absensi tenaga pendidik dan kemudian jurnal pembelajaran di dalam kelas. Kemudian wali murid dapat memberikan informasi jika ada tingkah laku tenaga pendidik yang kurang sesuai dalam menjalankan tugasnya.

Kepala sekolah memberikan teguran kepada tenaga pendidik yang melalaikan tugasnya, namun menggunakan pendekatan dan metode persuasif sehingga tenaga pendidik kedepannya tidak lagi melalaikan tugasnya di sekolah. Kepala sekolah sangatlah memperhatikan strategi tenaga pendidik dalam menjalankan tugasnya, sebab dengan efektif dan efisiennya tenaga pendidik dalam menjalankan tugasnya, maka akan berdampak positif terhadap keberhasilan sekolah dalam mencapai prestasi baik secara akademik maupun non akademik. Hasil penelitian Hidayati (2014) menjelaskan sebagai berikut: kepemimpinan pendidikan yang baik sangat mempengaruhi mutu pendidikan. Peran kepemimpinan pendidikan sangat menunjang keberhasilan tenaga pendidik.

SD IT Mutiara Cendekia Lubuklinggau, sangatlah menerima kritik dan saran yang sifatnya membangun demi perbaikan-perbaikan kedepannya terutama saran untuk tenaga pendidik dalam menjalankan tugas pokok dan fungsinya baik sebagai tenaga pengajar dan pendidik maupun pengelolaan administrasi sekolah, sehingga dapat memberikan pelayanan terbaik kepada siswa dan dapat meningkatkan prestasi sekolah baik secara akademik maupun non akademik.

\section{Evaluasi Tenaga Pendidik}

Berdasarkan hasil wawancara di atas, maka eveluasi tenaga pendidikSD IT Mutiara Cendekia sebagai berikut kepala sekolah menggunakan instrumen angket yang disebarkan kepada siswa dan kotak saran sehingga kepala sekolah mengetahui kekuatan dan kelemahan masing-masing guru dan kemudian diberikan masukan dan pembinaan agar kedepan tidak mengulanginya lagi. Kepala sekolah sangatlah fokus dalam upaya peningkatan kinerja tenaga pendidik dan pendidikan, dengan berbagai macam upaya, yakni dengan pelatihan dan pembinaan, agar kinerja tenaga pendidik selalu meningkat dan berdampak positif terhadap kemajuan sekolah.

Kepala sekolah sangatlah memperhatikan kekuatan dan kelemahan tenaga pendidik. Kekuatan tenaga pendidik dihargai dan kelemahannya dimotivasi agar menjadi kekuatan untuk mendukung kemajuan sekolah. Kepala sekolah menganalisis kendala-kendala yang dialami tenaga pendidik dalam menjalankan tugasnya, agar kendala-kendala dan hambatan tidak menganggu dalam usaha pencapain prestasi belajar siswa dan prestasi sekolah baik secara akademik maupun non akademik. 


\section{SIMPULAN}

Perencanaan tenaga pendidikSDIT Mutiara Cendekia Lubuklinggau berjalan dengan baik seperti ratio guru dan siswa (2/22) sangat ideal dan sesuai dengan standar, memetakan kebutuhan guru dan tata usaha berdasarkan spesifikasi dan keahlian, dan perekrutan tenaga pendidik melakukan test kemampuan baca-tulis alqur`an dan test micro teaching, sedangkan tenaga kependidikan hanya baca-tulis alqur`an.

Pelaksananaan tenaga pendidik di SDIT Mutiara Cendekia Lubuklinggau, yakni pola rekrutmen tenaga pendidik yakni; a) Seleksi administrasi berkas lamaran pekerjaan, b) tes kemampuan baca al-Qur'an dan tes micro teaching. Tenaga pendidik dibina dengan metode yanbu'a, seperti membaca al-qur'an mengkaji kitab fathul qorib dan matan takrib yang dilaksanakan secara terjadwal, kemudian pembinaan dari yayasan dilaksanakan satu bulan sebanyak 2 kali, rutin pelatihan kurikulum 2013 dan seminar pengembangan mutu guru yang professional

Kepala sekolah SDIT Mutiara Cendekia Lubuklinggau melakukan kontrol kepada tenaga pendidik dengan cara kepala sekolah melakukan kegiatan keliling ruangan selama proses pembelajaran berlangsung dan kemudian kepala sekolah memeriksa absensi tenaga pendidik, kemudian jurnal pembelajaran di dalam kelas. Wali murid dapat memberikan informasi jika ada tingkah laku tenaga pendidik yang kurang sesuai dalam menjalankan tugas di sekolah.

Untuk melakukan evaluasi terhadap tenaga pendidik kepala sekolah menggunakan instrumen angket yang disebarkan kepada siswa dan kotak saran sehingga kepala sekolah mengetahui kekuatan dan kelemahan tenaga pendidik dan kemudian diberikan pelatihan, pembinaan motivasi dan masukan agar tenaga pendidik SDIT Mutiara Cendekia Lubuklinggau lebih berkualitas dalam menjalankan tugasnnya masing-masing. 


\section{DAFTAR PUSTAKA}

Hidayati, H. (2014). Manajemen Pendidikan, Standar Pendidikan, Tenaga Kependidikan dan Mutu Pendidikan. Jurnal Al-Talim, 21(2)

Manaf, M. (2013). Manajemen Tenaga pendidik. Jurnal Ta'lim Muta 'lim, 3(5)

Muhadjir, M. (1999). Metode Penelitian Kualitatif. Bandung: Alphabeta

Muzyanah, M. (2014). Manajemen Sekolah sebagai Media Strategis Pendiidkan Karakter. Jurnal Analisa, 2(1)

Peraturan Pemerintah RI No. 19 tahun 2005 tentang Standar Nasional Pendidikan Jakarta: Sinar Grafika

Suwardi, S., \& Samino, S. (2014). Kepemimpinan Kepala Sekolah dalam Pengembangan Lembaga Pendidikan Islam Sekolah Kreatif SD Muhammadiya Kota Madiun. Jurnal Manajemen Pendidikan, 9(2)

Undang-undang No. 20 tahun 2003 tentang Sistem Pendidikan Nasional 